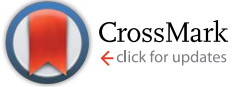

Cite this: RSC Adv., 2017, 7, 16938

Received 29th November 2016 Accepted 5th March 2017

DOI: $10.1039 / c 6 r a 27508 g$

rsc.li/rsc-advances

\section{The role of interactions between abrasive particles and the substrate surface in chemical-mechanical planarization of $\mathrm{Si}-$ face $6 \mathrm{H}-\mathrm{SiC}$}

\author{
Guomei Chen, Zifeng Ni, ${ }^{*}$ Yawen Bai, Qingzhong Li and Yongwu Zhao*
}

\section{Introduction}

A silicon carbide ( $\mathrm{SiC}$ ) single crystal has been considered to be an ideal material for high-temperature and high-frequency optoelectronic devices because of its high breakdown voltage, good electron mobility, wide band gap and excellent thermal conductivity. A flat and damage-free substrate surface is crucial for its applications and can potentially be achieved using CMP processes. ${ }^{1-5}$ However, it is difficult to obtain this desired surface with good material removal rates (MRR), due to its unique properties (e.g. high hardness and chemical stability).

Substantial research efforts have been made to improve the MRR of SiC single-crystal substrates with minimally damaged surfaces during the CMP process using silica/ceria abrasives. ${ }^{6-10}$ It was suggested that surface oxidation was essential for the CMP of the SiC substrate. It was initially proposed that the $\mathrm{OH}^{-}$ group weakens the $\mathrm{Si}-\mathrm{C}$ bonds and increases the chemical reaction rate of the surface atoms during the CMP process. ${ }^{11}$ Yagi et al. analyzed the $4 \mathrm{H}$-SiC surface after it had been dipped in a mixture of $\mathrm{FeSO}_{4}$ and $\mathrm{H}_{2} \mathrm{O}_{2}$ solution for $3 \mathrm{~h}$ and found that the C-plane was more easily oxidized than the Si-plane. They continued by reporting that the oxidized product could be

School of Mechanical Engineering, Jiangnan University, Wuxi, Jiangsu 214122, China. E-mail: nizf@jiangnan.edu.cn; zhaoyw@jiangnan.edu.cn removed by dissolving it in potassium hydroxide solution. ${ }^{\mathbf{1 2}}$ Furthermore, Li et al. explored a two-step electrochemical mechanical planarization (ECMP) process to polish the Si-face 4H-SiC substrate. The SiC substrate surface first underwent anodic oxidization by hydrogen peroxide using potassium nitrate as an electrolyte, then it was polished with colloidal silica slurries at pH 10 to remove the oxide layer. ${ }^{13}$ Deng et al. investigated a ceria-slurry-based ECMP process in which anodic oxidation and abrasive polishing were combined efficiently to flatten single-crystal SiC substrates. ${ }^{\mathbf{1 4}}$ However, the polishing mechanism of the SiC substrate during the CMP process was not fully understood, involving electrostatic interactions between the abrasives and the $6 \mathrm{H}$-SiC substrate. The interactions between the slurry particles and the wafer surface affect the MRR of the wafer during the CMP process. Meanwhile, the adhesion of abrasive particles to polished surfaces may cause contaminants and defects. Volkov et al. studied the influence of the adhesion of silica and ceria abrasive nanoparticles on the CMP of silica surfaces and found that high adhesion was associated with a higher number of defects. They went on to report that higher adhesion correlated with higher removal rates when polishing with ceria slurries. ${ }^{15} \mathrm{Lu}$ et al. reported that the polishing efficiency of the substrate was strongly affected by the attractiveness of the slurry particles to the polished surface. ${ }^{\mathbf{1 6}}$ Abiade et al. found that a high removal rate was 
related to the actual participating abrasives during the CMP process and that the agglomeration of slurry particles could lead to a high number of surface defects. ${ }^{17}$ Sreeremya et al. revealed that the material removal and the final surface quality were affected mostly by the morphology of the ceria-based abrasives and that the quality of the polished surface could be improved by improving the dispersion of the abrasives. ${ }^{18}$ Furthermore, the interaction between the abrasives and the polished surface could be changed by modifying the surface charge of the abrasives and the wafer to influence the material removal during the CMP process. ${ }^{19,20}$ Lagudu et al. studied the influence of the ionic strength on material removal during the CMP of amorphous SiC film using silica slurries and suggested that the electrostatic repulsion between the silica abrasive and the SiC film was reduced by the addition of an ionic compound, thereby increasing the material removal. ${ }^{21}$ Therefore, the MRR of the SiC substrate could be increased, surface defects might be reduced and contaminants could be avoided, through a fundamental understanding of the role of the interactions between the abrasive particles and the wafer surface. Though there are few studies reported on the effect of particle type, slurry $\mathrm{pH}$ and oxidant, ${ }^{22-24}$ no detailed studies have been conducted on the role of the interaction between $\mathrm{SiO}_{2}$ or $\mathrm{CeO}_{2}$ nanoparticles and the surface in the CMP of SiC single crystal substrates.

In this paper, the electrostatic interactions between the abrasive particles (silica and ceria) and the $6 \mathrm{H}$-SiC substrate surfaces were studied by measuring the zeta potential of the abrasives in slurries with varied $\mathrm{pH}$ values. Also the adhesion of particles to the $6 \mathrm{H}$-SiC polished surfaces in different slurries with varied $\mathrm{pH}$ values were observed using scanning electron microscope (SEM) measurements, and the attractive/repulsive forces between the charged silica/ceria nanoparticles and the $6 \mathrm{H}$-SiC wafer surfaces in aqueous solution were calculated using the classical Derjaguin-Landau-Verwey-Overbeek (DLVO) theory model, which accounts for van der Waals interactions and electrostatic double layer interactions. Furthermore, the influence of the adhesion of abrasive particles to the wafer surfaces in the absence and presence of $\mathrm{KMnO}_{4}$ on the friction coefficients during the CMP of Si-face $6 \mathrm{H}-\mathrm{SiC}$ was also studied through friction tests. The effect of $\mathrm{KMnO}_{4}$ on the surface oxidation of Siface $6 \mathrm{H}$-SiC was analyzed by X-ray photoelectron spectroscopy (XPS). Finally, the role of interaction between the abrasives and surfaces on the CMP performance of Si-face $6 \mathrm{H}$-SiC substrates is discussed, based on the zeta potential, SEM images, DLVO theoretical predictions, friction coefficient, polishing experiments and XPS analysis.

\section{Materials and experimental methods}

\subsection{Materials}

Commercially available n-type, 2-inch diameter Si-face (0001) $6 \mathrm{H}-\mathrm{SiC}$ single crystal wafers (TanKeBlue Semiconductor Co. Ltd., Beijing, China) were used in the experiments. Silica abrasives $\left(d_{\text {mean }} \sim 80 \mathrm{~nm}, 30 \mathrm{wt} \%\right.$, Jingrui New materials Co. Ltd., Xuancheng, China) and ceria abrasives $\left(d_{\text {mean }} \sim 120 \mathrm{~nm}, 30\right.$ wt\%, Chuangyuan New materials Co. Ltd., Suzhou, China) were obtained as colloidal dispersions and diluted to use at different particle concentrations. These two abrasive nanoparticles were characterized by transmission electron microscopy (TEM, JEOL2100, Japan), as shown in Fig. 1. The chemical additives, potassium hydroxide ( $\mathrm{KOH}, \geq 85 \%$ ), nitric acid (aq. $\mathrm{HNO}_{3}, 70 \%$ ) and potassium permanganate $\left(\mathrm{KMnO}_{4}, \geq 99 \%\right)$ were supplied by China National Pharmaceutical Co. Ltd. and used without further purification. In this study, the concentrations of silica particles and ceria particles were maintained at $6 \mathrm{wt} \%$ and 2 $\mathrm{wt} \%$, respectively, based on the results of orthogonal experiments in our previous work.

\subsection{Sample preparation}

Before testing, the $6 \mathrm{H}-\mathrm{SiC}$ wafer was pre-polished with slurries containing only $6 \mathrm{wt} \%$ colloidal silica at $\mathrm{pH} 8$ to remove the native oxide layer on the as-received $6 \mathrm{H}$-SiC substrate surface. During the dipping process, the SiC samples were dipped in four different slurries ( $6 \mathrm{wt} \%$ silica, $6 \mathrm{wt} \%$ silica $+0.05 \mathrm{M}$ $\mathrm{KMnO}_{4}, 2 \mathrm{wt} \%$ ceria, $2 \mathrm{wt} \%$ ceria $+0.05 \mathrm{M} \mathrm{KMnO}_{4}$ ) for $2 \mathrm{~min}$ at $\mathrm{pH}$ values of $2,4,6,8$ and 10 , respectively. Then, these dipped
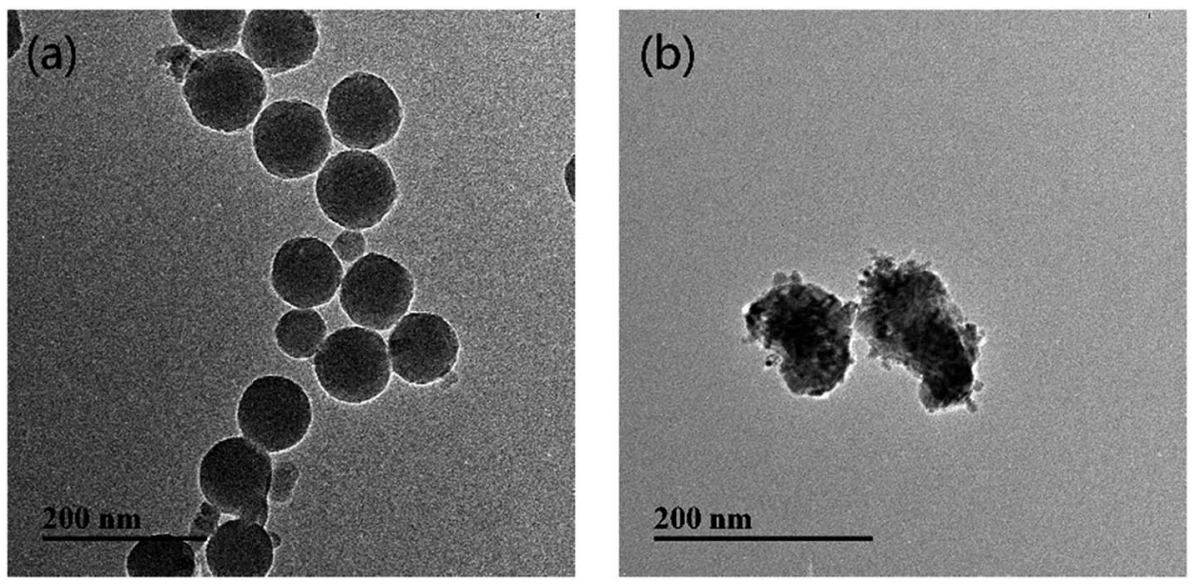

Fig. 1 The TEM images of the abrasive nanoparticles: (a) silica; (b) ceria. 
samples were sonicated in DI water with the same $\mathrm{pH}$ value as their dipped slurries for $10 \mathrm{~min}$. Finally, all these samples were dried in air. The slurries were obtained by mixing chemical additives with deionized water, then adding abrasive particles to this solution and stirring for $10 \mathrm{~min}$. The $\mathrm{pH}$ values of the slurries were adjusted by nitric acid or potassium hydroxide. For XPS analysis, SiC samples were first oxidized by immersion into the $\mathrm{KMnO}_{4}(0.05 \mathrm{M})$ solution at $\mathrm{pH} 6$ for $3 \mathrm{~h}$. To dissolve the oxide formed above, the sample was further dipped in a solution of $\mathrm{KOH}$ at $\mathrm{pH} 12$ for $3 \mathrm{~h}$. These samples were subsequently rinsed with DI water and dried in air.

\subsection{Polishing of $6 \mathrm{H}-\mathrm{SiC}$ substrates}

The polishing experiments were performed on a 1200S polishing machine (Kejing Auto-Instrument Co., Ltd, Shenyang, China) using an IC-1000 pad (Dow Electronic Materials, Newark, DE). Each SiC substrate was polished for $20 \mathrm{~min}$ at $4 \mathrm{psi}$ down pressure with a platen/carrier speed of $80 / 80 \mathrm{rpm}$ and

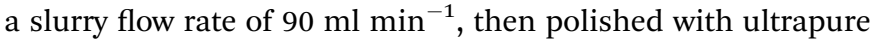
water for $1 \mathrm{~min}$ to remove any particles left on the polished surface. The polished pad was ex situ conditioned with a diamond grit conditioner. The MRR was calculated from the weight loss of the SiC substrate before and after polishing. The surface topography was characterized by atomic force microscopy (AFM, Rtec instruments, USA).

\subsection{Friction test}

The friction tests were performed on an Rtec tribometer (MFT 5000 , Rtec instruments, USA) using the pin-on-disc technique. During the tests $(n=3)$, the 2 -inch Si-face $6 \mathrm{H}$-SiC substrate was fixed in a plastic container, which was driven by an electric rotator at a speed of $2 \mathrm{rpm}$ and reciprocated in the $X$ direction. A polyurethane pad (IC1000, Dow Electronic Materials) with a diameter of $5 \mathrm{~mm}$ was stuck to a stainless steel pin and pressed against the $6 \mathrm{H}$-SiC substrate which was immersed in different slurries. The tests were conducted under a load of 4 psi for $5 \mathrm{~min}$ with a reciprocating amplitude of $10 \mathrm{~mm}$ and a frequency of $2 \mathrm{~Hz}$. Before each test, the $6 \mathrm{H}-\mathrm{SiC}$ substrate was pre-polished with $6 \mathrm{wt} \% \mathrm{SiO}_{2}$ at pH 8 for $5 \mathrm{~min}$ and each pad was used only once. All these experiments were conducted at room temperature.

\subsection{Characterization techniques}

The zeta potentials of colloidal silica and ceria particles in DI water in the $\mathrm{pH}$ range from 2 to 11 were measured using a zeta plus particle apparatus (Nano-ZS, Malvern). The adhesion of nanoparticles to the wafer surfaces was characterized by SEM (Hitachi SU8020, Japan). All XPS experiments were completed on an RBD upgraded PHI-5000C ESCA system (PerkinElmer) with $\mathrm{Mg} \mathrm{K} \alpha$ radiation $(h \nu=1253.6 \mathrm{eV})$ or $\mathrm{Al} \mathrm{K} \alpha$ radiation $(h \nu=$ $1486.6 \mathrm{eV}$ ). The X-ray anode was operated at $250 \mathrm{~W}$, the high voltage was maintained at $14.0 \mathrm{kV}$ with a detection angle at $54^{\circ}$ and the base pressure of the analyzer chamber was around $5 \times 10^{-8} \mathrm{~Pa}$.

\section{Results and discussion}

\subsection{Zeta potential}

Electrostatic interactions between the abrasive particles and the SiC surface play an important role in particle adhesion during the CMP process. To investigate these electrostatic interactions, zeta potentials of the silica and ceria particles were measured over the $\mathrm{pH}$ range from 2 to 11, as shown in Fig. 2. As is well known, the zeta potentials of silica particles in DI water are negative in the $\mathrm{pH}$ range $2-11$, and the absolute value of the (negative) zeta potential increases with an increase of $\mathrm{pH}$ value from 2 to 7 , then it tends to be stable from $\mathrm{pH} 8$ to 11. The zeta potentials of ceria particles in DI water, by contrast, were positive when $\mathrm{pH}<7$ and negative when $\mathrm{pH}>8$. The absolute value of the zeta potential decreased from $\mathrm{pH} 2$ to 7 , then increased from pH 8 to 11 . The iso-electric point (IEP) of ceria in DI water was found at around $\mathrm{pH} 7$, similar to the reported values around $\mathrm{pH} 6-8 .{ }^{25-28}$ In addition, the IEP of SiC in DI water was around $\mathrm{pH} 5 .^{29}$ Therefore, silica particles are expected to adhere to the SiC surface in the $\mathrm{pH}$ range $2-5$, while ceria particles are likely to adhere to the SiC surface in the $\mathrm{pH}$ range $5-7$.

\subsection{SEM measurements}

The adhesion of the silica and ceria particles to the pre-polished $6 \mathrm{H}$-SiC surfaces in four different slurries with five $\mathrm{pH}$ values $\mathrm{pH}$ 2, pH 4, pH 6, pH 8 and pH 10) were observed using SEM. The SEM image of the as-received $6 \mathrm{H}-\mathrm{SiC}$ substrate clearly showed that there were no particles on the $6 \mathrm{H}$-SiC surface, as shown in Fig. 3. After dipping in silica based slurries (6 wt\% silica), a number of silica particles were present on the $6 \mathrm{H}-\mathrm{SiC}$ surface at pH 2 (Fig. 4a) and pH 4 (Fig. 4b) and no particles were present at pH 6 (Fig. 4c), pH 8 (Fig. 4d) or pH 10 (Fig. 4e). These observations were consistent with the analysis of zeta potentials (Fig. 2). Since the surfaces of the silica particles and the $6 \mathrm{H}-\mathrm{SiC}$ substrate were oppositely charged below $\mathrm{pH} 5$, they were expected to attract each other at $\mathrm{pH} 2$ and $\mathrm{pH} 4$, and the silica particles appear to be distributed on the $6 \mathrm{H}$-SiC surface. On the

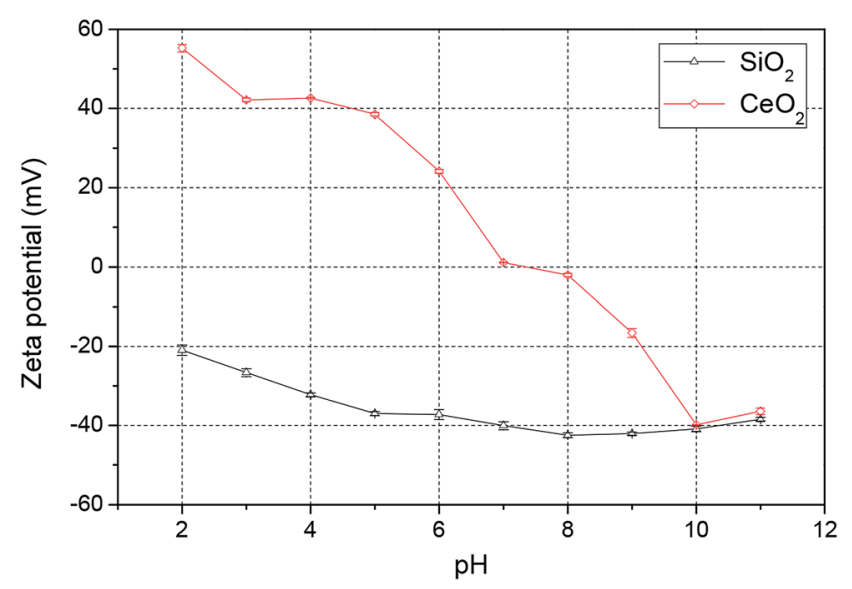

Fig. 2 Zeta potential of colloidal silica and ceria nanoparticles in DI water over the $\mathrm{pH}$ range $2-11$. 


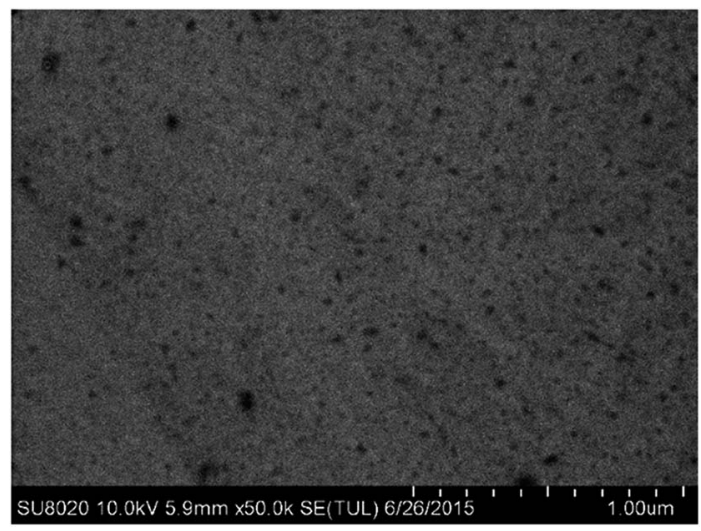

Fig. 3 The SEM image of the as-received $6 \mathrm{H}-\mathrm{SiC}$ substrate.

other hand, the silica particles and the $6 \mathrm{H}$-SiC surface were expected to repel each other at $\mathrm{pH} 6, \mathrm{pH} 8$ and $\mathrm{pH} 10$, due to having the same charge above $\mathrm{pH} 5$.
Fig. 5 shows the SEM images of the $6 \mathrm{H}$-SiC substrates dipped in silica based slurries in the presence of $\mathrm{KMnO}_{4}$. It can be seen that a lot of aggregated silica particles adhered to the $6 \mathrm{H}-\mathrm{SiC}$ surface at pH 2 (Fig. 5a) and pH 4 (Fig. 5b), there were a few aggregated silica particles at $\mathrm{pH} 6$ (Fig. 5c) and no aggregated silica particles at pH 8 (Fig. 5d) or pH 10 (Fig. 5e). This can be attributed to the fact that the aggregation of silica particles was accelerated by adding $\mathrm{KMnO}_{4}$ and would be affected by a more heterogeneous surface. If the surface oxidation was enhanced by $\mathrm{KMnO}_{4}$, the attractive interaction between silica particles and the oxidized surface would be weakened, and the amount of absorbed particles would also be reduced..$^{30}$ However, from Fig. 4 and 5, it can clearly be seen that the amount of aggregated particles did not decrease at $\mathrm{pH} 2$ and $\mathrm{pH} 4$, suggesting that the aggregation might not be influenced by the surface heterogeneity. Due to the good stability of silica particles and the large repulsive force between silica particles and the substrate surface at high $\mathrm{pH}$ values, ${ }^{31}$ it was hard to observe any aggregated silica particles on the dipped $6 \mathrm{H}-\mathrm{SiC}$ surface at $\mathrm{pH} 8$ and $\mathrm{pH} 10$.
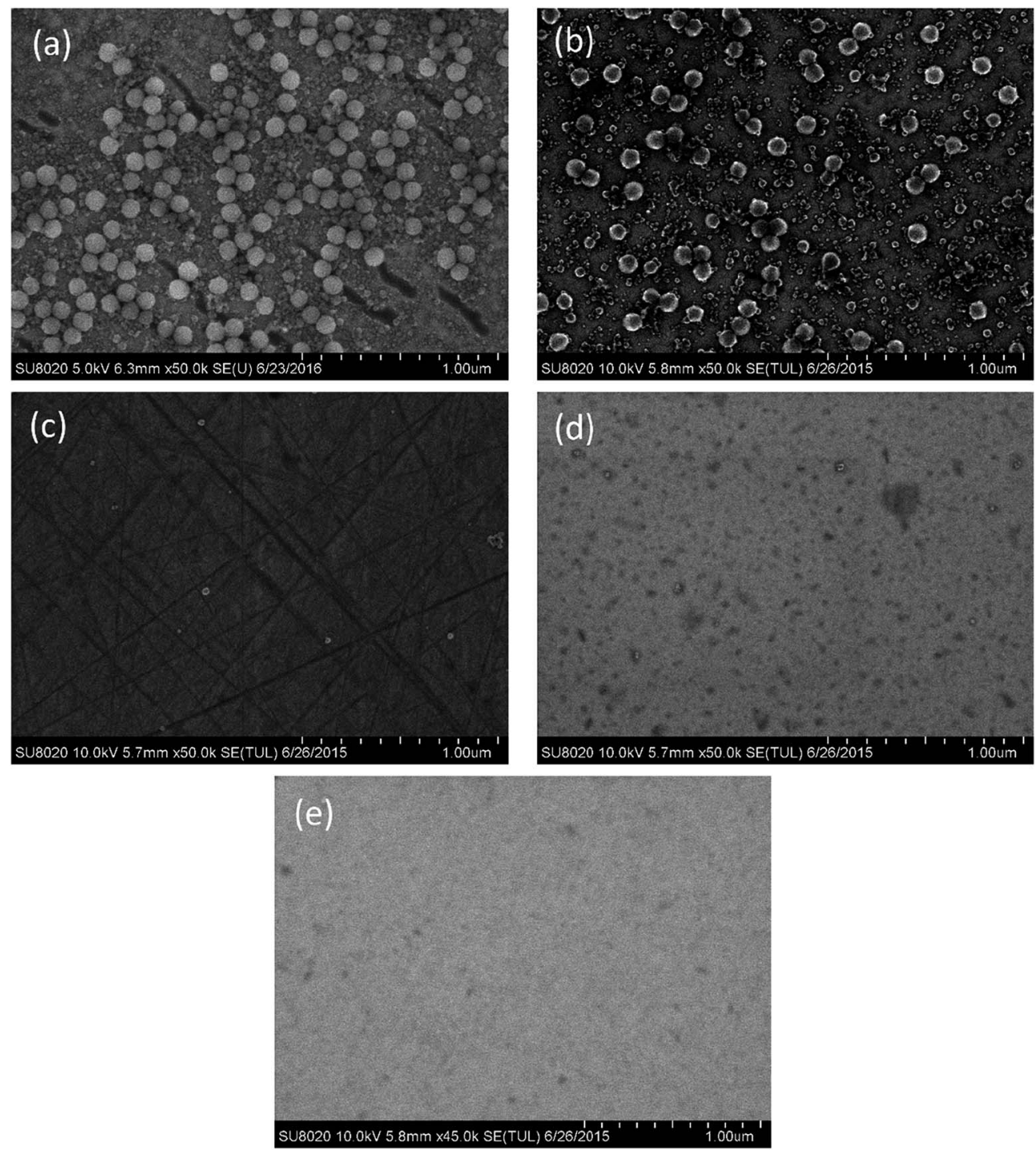

Fig. 4 The SEM images of the $6 \mathrm{H}-\mathrm{SiC}$ substrate dipped in silica based slurries at (a) $\mathrm{pH} 2$, (b) pH 4, (c) pH 6, (d) $\mathrm{pH} 8$ and (e) $\mathrm{pH} 10$. 

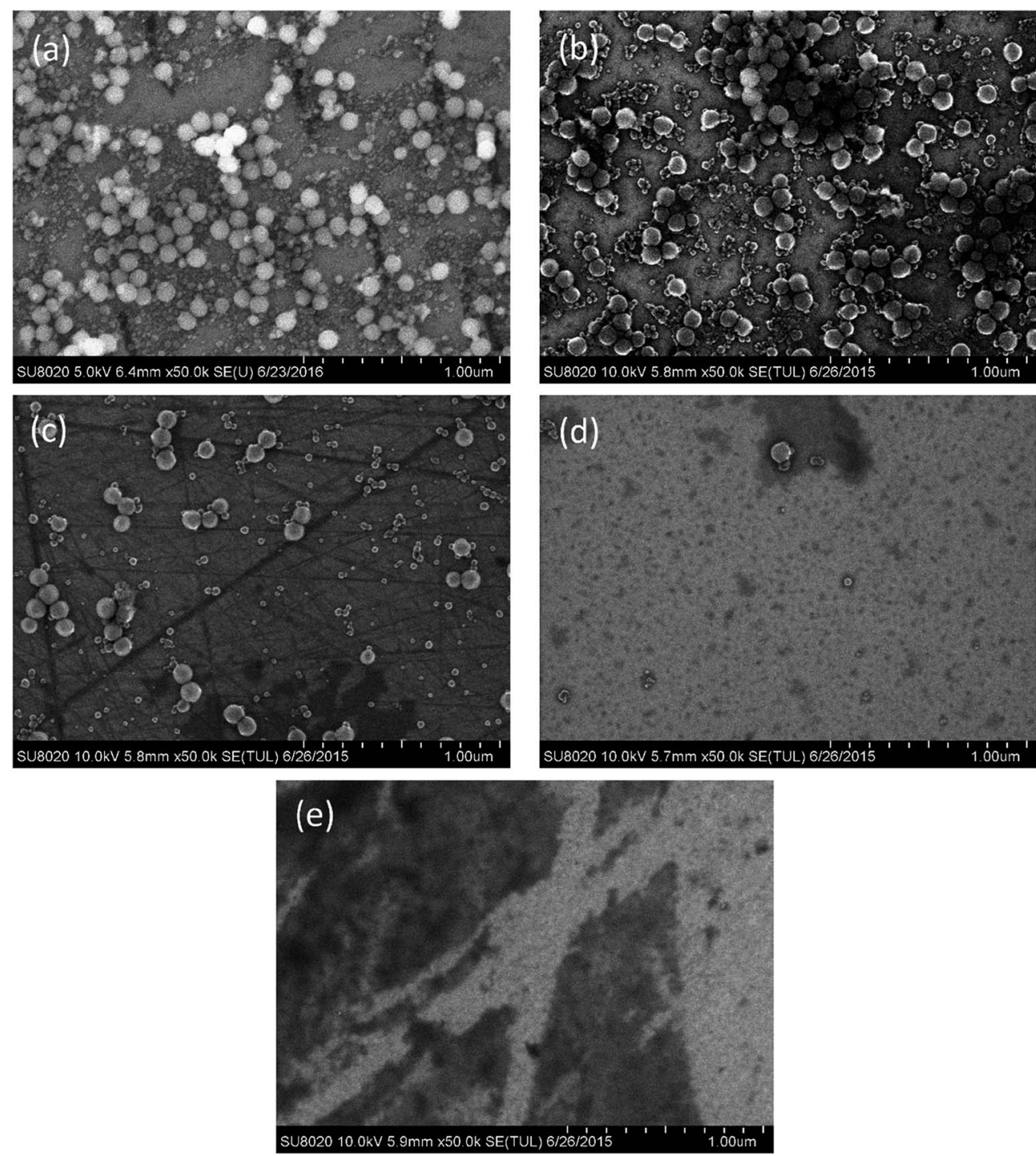

Fig. 5 The SEM images of the $6 \mathrm{H}-\mathrm{SiC}$ substrate dipped in silica $+\mathrm{KMnO}_{4}$ based slurries at (a) $\mathrm{pH} 2$, (b) $\mathrm{pH} 4$, (c) $\mathrm{pH} 6$, (d) $\mathrm{pH} 8$ and (e) $\mathrm{pH} 10$.

The adhesion of ceria particles to the $6 \mathrm{H}$-SiC surface at varied $\mathrm{pH}$ values, by contrast, was different from that of silica particles, as shown in Fig. 6. It can be clearly seen that a large number of ceria particles attached to the $6 \mathrm{H}-\mathrm{SiC}$ surface at $\mathrm{pH} 2$ (Fig. $6 \mathrm{a}$ ) and pH 4 (Fig. 6b), fewer at pH 6 (Fig. 6c) and pH 10 (Fig. 6e), and many fewer at pH 8 (Fig. 6d). According to the analysis of zeta potentials, the ceria particles were expected to be repelled by the same charged $6 \mathrm{H}$-SiC surface below $\mathrm{pH} 5$ and above $\mathrm{pH} 8$. However, a lot of ceria particles still existed on the $6 \mathrm{H}$-SiC surface at $\mathrm{pH} 2, \mathrm{pH} 4$ and $\mathrm{pH} 10$. This might be because the ceria particles possess a chemical tooth and the $\mathrm{Si}-\mathrm{O}-\mathrm{Ce}$ bonds were formed between ceria particles and the $6 \mathrm{H}-\mathrm{SiC}$ surface. ${ }^{32} \mathrm{~A}$ similar phenomenon was observed on the $6 \mathrm{H}$-SiC surfaces dipped in ceria based slurries in the presence of $\mathrm{KMnO}_{4}$, as shown in Fig. 7.

\subsection{DLVO interactions}

To estimate the repulsive/attractive forces between a charged $6 \mathrm{H}-\mathrm{SiC}$ plate and a charged silica or ceria particle, the DLVO interactions were considered.
The total DLVO of the plate-sphere interaction energy $\left(W_{\mathrm{T}}\right)$ is given by ${ }^{33}$

$$
W_{\mathrm{T}}=W_{\mathrm{E}}+W_{\mathrm{A}}
$$

The energies of electrostatic interaction between the surface of a plate and a spherical layer $\left(W_{\mathrm{E}}\right)$ are calculated using constant charge condition as ${ }^{34,35}$

$$
\begin{aligned}
W_{\mathrm{E}}= & -\pi \varepsilon \varepsilon_{0} R\left\{\left(\psi_{1}+\psi_{2}\right)^{2} \ln [1-\exp (-\kappa D)]\right. \\
& \left.+\left(\psi_{1}+\psi_{2}\right)^{2} \ln [1+\exp (-\kappa D)]\right\}
\end{aligned}
$$

where $\varepsilon(=78.5)$ is the relative dielectric constant of water, $\varepsilon_{0}$ $\left(=8.854 \times 10^{-12} \mathrm{C} \mathrm{V}^{-1} \mathrm{~m}^{-1}\right)$ is the permittivity of vacuum, $R$ is the particle diameter, $\psi_{1}$ or $\psi_{2}$ is the surface potential, $D$ is the separation distance, $\kappa$ is the inverse Debye length. ${ }^{36}$

The energies of van der Waals interaction $\left(W_{\mathrm{A}}\right)$ can be calculated according to to $^{37,38}$

$$
W_{\mathrm{A}}=-A_{132} R / 6 D
$$



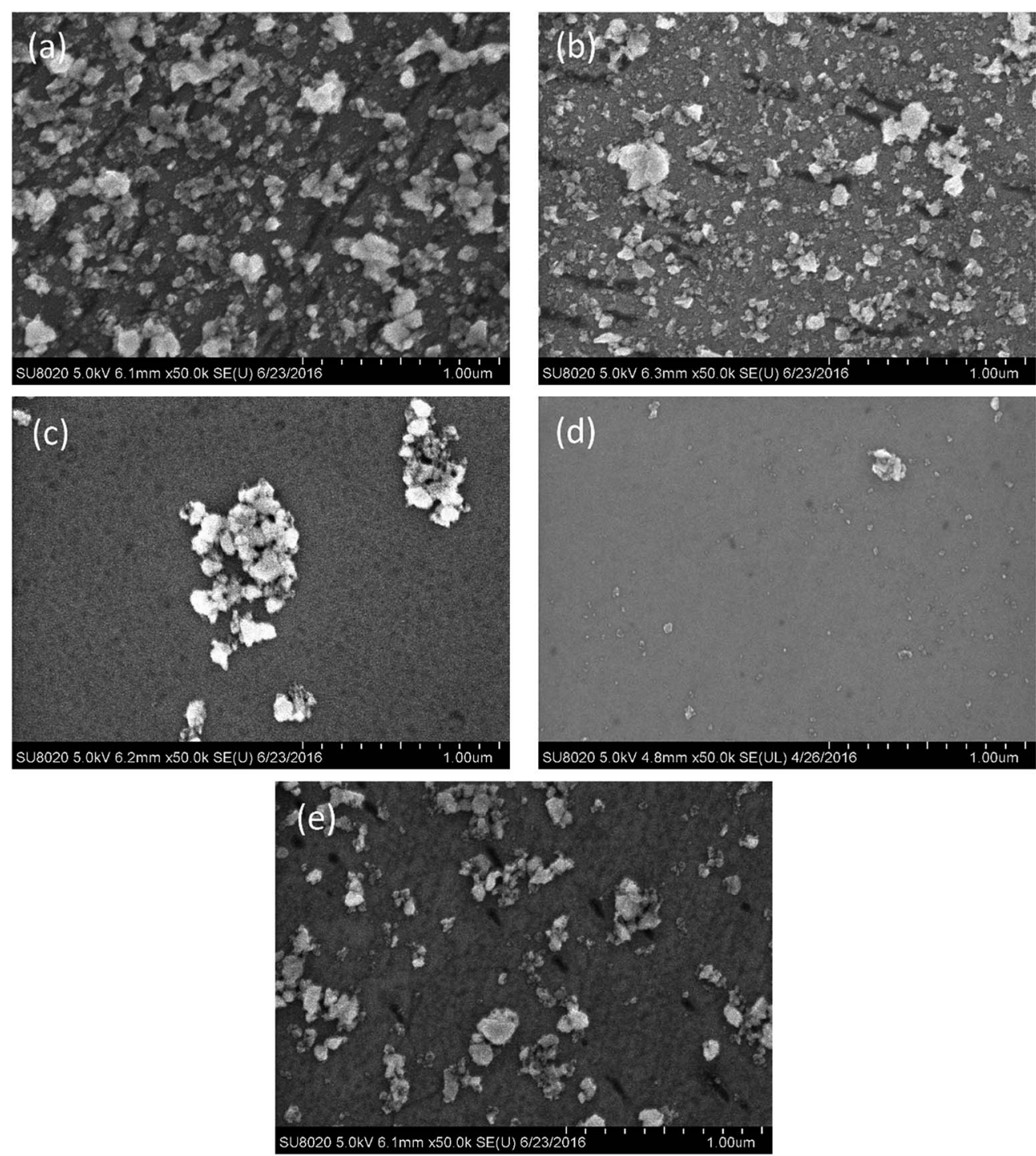

Fig. 6 The SEM images of the 6H-SiC substrate dipped in ceria based slurries at (a) pH 2, (b) pH 4, (c) pH 6, (d) $\mathrm{pH} 8$ and (e) $\mathrm{pH} 10$.

where $A_{132}$ is the Hamaker constant of two adjacent materials 1 and 2 , interacting across medium 3 , and can be calculated according to ${ }^{39}$

$$
A_{132} \approx\left(A_{131} A_{232}\right)^{1 / 2}
$$

The Hamaker constants for the $6 \mathrm{H}-\mathrm{SiC}-$ water-silica and $6 \mathrm{H}-$ SiC-water-ceria interactions were calculated to be $3.3 \times 10^{-20} \mathrm{~J}$ and $8.5 \times 10^{-20} \mathrm{~J}$, respectively. ${ }^{40-42}$

The total force $\left(F_{\mathrm{T}}\right)$ between the plate and the sphere is defined as $^{43}$

$$
F_{\mathrm{T}}=-d W_{\mathrm{T}} / d D
$$

According to eqn (1)-(3) and (5), the force/R-separation distance between the $6 \mathrm{H}$-SiC surface and the silica or ceria particle under different environments can be modeled. In this study, it was assumed that the charged particles were spherical and that the surface potentials were equal to the zeta potentials of the surface. The background electrolyte was considered to be 1-1 type with a concentration of $1 \times 10^{-3} \mathrm{M}$. The zeta potentials of $\mathrm{SiC}$ were set as $30 \mathrm{mV}$ at $\mathrm{pH} 4,-56 \mathrm{mV}$ at $\mathrm{pH} 6,-96 \mathrm{mV}$ at $\mathrm{pH}$ 8 and $-125 \mathrm{mV}$ at $\mathrm{pH} 10$, respectively. Fig. 8 shows the theoretical DLVO forces between the $6 \mathrm{H}$-SiC surface and a silica particle in $1 \times 10^{-3} \mathrm{M} \mathrm{KNO}_{3}$ solutions at different $\mathrm{pH}$ values. It can be clearly seen that an attractive electrostatic interaction was present at $\mathrm{pH} 4$, due to the attraction induced by the oppositely charged surfaces between $\mathrm{SiC}$ and silica. While at high $\mathrm{pH}$ levels $(\mathrm{pH}=6,8,10)$, the repulsive force played a dominant role at long separation distances, and it went up with an increase in $\mathrm{pH}$ values. At short separations, the force changed to attractive, which can be understood by combining the electrostatic force and the van der Waals force (vdW force). At high $\mathrm{pH}$ values, the surfaces of SiC and silica were both negatively charged. Therefore, a repulsive electrostatic interaction existed between the similarly charged $\mathrm{SiC}$ and silica surfaces at longer separation distances. While at a short 

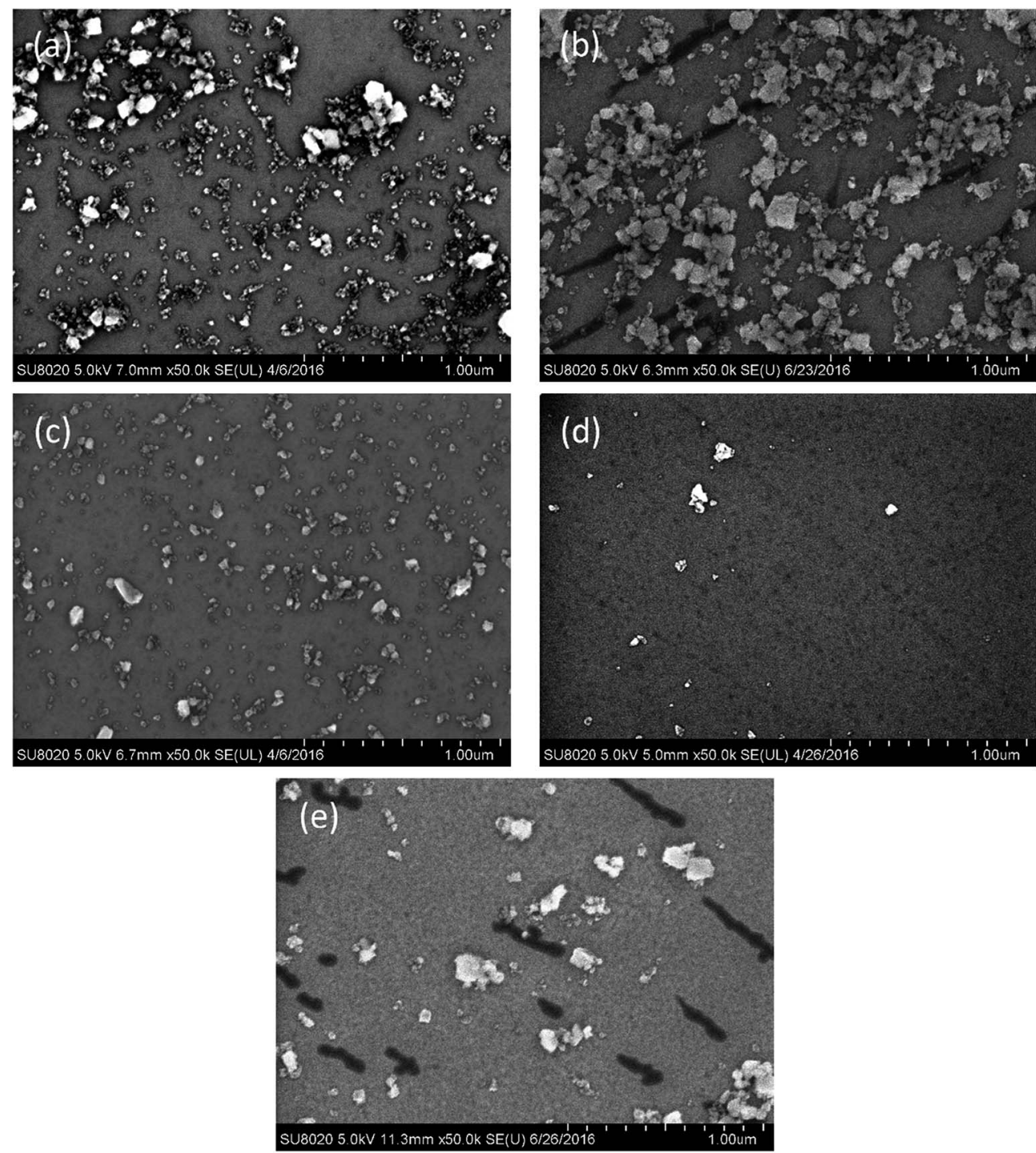

Fig. 7 The SEM images of the $6 \mathrm{H}-\mathrm{SiC}$ substrate dipped in ceria $+\mathrm{KMnO}_{4}$ based slurries at (a) $\mathrm{pH} 2$, (b) $\mathrm{pH} 4$, (c) $\mathrm{pH} 6$, (d) $\mathrm{pH} 8$ and (e) $\mathrm{pH} 10$.

distance, the vdW force was dominant and the total interaction force became attractive. An attractive force between the surfaces of $6 \mathrm{H}$-SiC and ceria particles in $1 \times 10^{-3} \mathrm{M} \mathrm{KNO}_{3}$ solutions was clearly seen at $\mathrm{pH} 6$ over the whole range of separation distances, as shown in Fig. 9. This was in good agreement with the attractive interaction between the negatively charged SiC surface and the positively charged ceria surface. However, when the surfaces of SiC and ceria had the same charges at $\mathrm{pH}$ values of 4,8 and 10 , the total forces were repulsive at long separation distances and became attractive at short distances due to the increasing vdW force.

The theoretical predictions of DLVO forces between the surfaces of the $6 \mathrm{H}$-SiC substrate and the silica nanoparticles were in good agreement with the experimental observations. Discrepancies were noted between the theoretical predictions and experimental observations for ceria nanoparticles. This may be due to the existence of non-DLVO interactions between the surfaces of the ceria particles and the $6 \mathrm{H}-\mathrm{SiC}$ plate, such as the chemical tooth of the ceria particle and the $\mathrm{Si}-\mathrm{O}-\mathrm{Ce}$ bonds formed between ceria particles and the $6 \mathrm{H}$-SiC surface. ${ }^{44}$ The adhesion force of silica nanoparticles (about 5-12 $\mathrm{nN}$ ) to the silica surface was reported to be noticeably higher than that of ceria nanoparticles (about $0.5-1.5 \mathrm{nN}$ ) at different $\mathrm{pH}$ values using the AFM-cantilever approach method. ${ }^{11}$ Therefore, the adhesion of the ceria nanoparticles to the $6 \mathrm{H}$-SiC surface resulting from the non-DLVO force was negligibly small.

\subsection{Friction coefficient}

In order to further understand the influence of the abrasives' adhesion to the wafer surface in the absence and presence of $\mathrm{KMnO}_{4}$ during the CMP of Si-face $6 \mathrm{H}$-SiC substrate, the friction coefficients between the pad and the $6 \mathrm{H}-\mathrm{SiC}$ substrate surface were investigated through friction tests. Fig. 10 shows the friction coefficients between the pad and the $6 \mathrm{H}$-SiC substrate surface immersed in DI water or $\mathrm{KMnO}_{4}$ solution in a $\mathrm{pH}$ range of 2-10. It can clearly be seen that the friction coefficient in DI water was higher than that in $\mathrm{KMnO}_{4}$ solution. The friction 


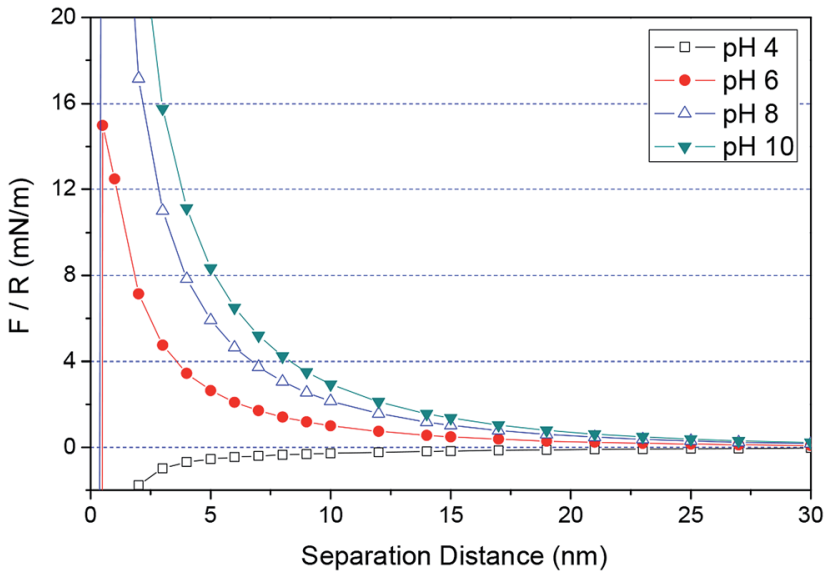

Fig. 8 The normalized forces between the surfaces of $6 \mathrm{H}-\mathrm{SiC}$ and silica particles as a function of separation distance at different $\mathrm{pH}$ values. The surface potentials of the $\mathrm{SiC}$ plate and silica particles are 30 and $-32 \mathrm{mV}$ at $\mathrm{pH} 4,-56$ and $-37 \mathrm{mV}$ at $\mathrm{pH} 6,-96$ and $-42 \mathrm{mV}$ at $\mathrm{pH}$ $8,-125$ and $-41 \mathrm{mV}$ at $\mathrm{pH} 10$, respectively. The Hamaker constant is $3.3 \times 10^{-20} \mathrm{~J}$ and the background electrolyte is $1 \mathrm{mM} \mathrm{KNO}_{3}$.

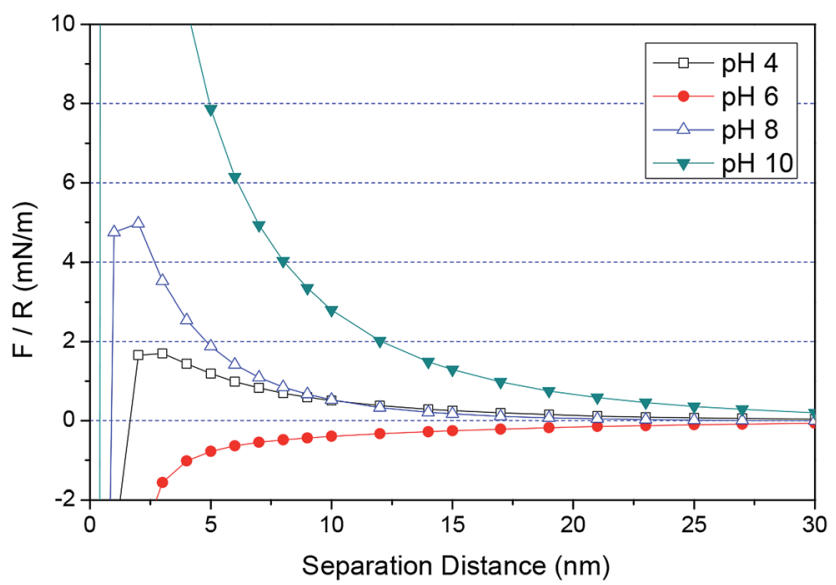

Fig. 9 The normalized forces between the surfaces of $6 \mathrm{H}-\mathrm{SiC}$ and ceria particles as a function of separation distance at different $\mathrm{pH}$ values. The surface potentials of the $\mathrm{SiC}$ plate and ceria particles are 30 and $43 \mathrm{mV}$ at $\mathrm{pH} 4,-56$ and $24 \mathrm{mV}$ at $\mathrm{pH} 6,-96$ and $-2 \mathrm{mV}$ at $\mathrm{pH} 8$, -125 and $-40 \mathrm{mV}$ at $\mathrm{pH} 10$, respectively. The Hamaker constant is 8.5 $\times 10^{-20} \mathrm{~J}$ and the background electrolyte is $1 \mathrm{mM} \mathrm{KNO}_{3}$.

coefficient in $\mathrm{KMnO}_{4}$ solution increased dramatically from $\mathrm{pH} 2$ to $\mathrm{pH} 6$, then fell slowly from $\mathrm{pH} 6$ to 10 . The lowest friction coefficient in $\mathrm{KMnO}_{4}$ solution was 0.13 at $\mathrm{pH}$ 2, which indicated that a new oxide layer might be formed on the $6 \mathrm{H}$-SiC substrate surface.

Fig. 11 compares the friction coefficients between the pad and the $6 \mathrm{H}$-SiC substrate surface immersed in the silica based slurries in the absence and presence of $\mathrm{KMnO}_{4}$ in a $\mathrm{pH}$ range of $2-10$. The particularly low friction coefficients in the silica based slurries were 0.10 at $\mathrm{pH} 2$ and 0.07 at $\mathrm{pH} 4$, indicating that the silica abrasives acted as ball bearings between the pad and the $6 \mathrm{H}$-SiC substrate surface. Higher friction coefficients were obtained at $\mathrm{pH} 6, \mathrm{pH} 8$ and $\mathrm{pH} 10$, due to the fact that the silica

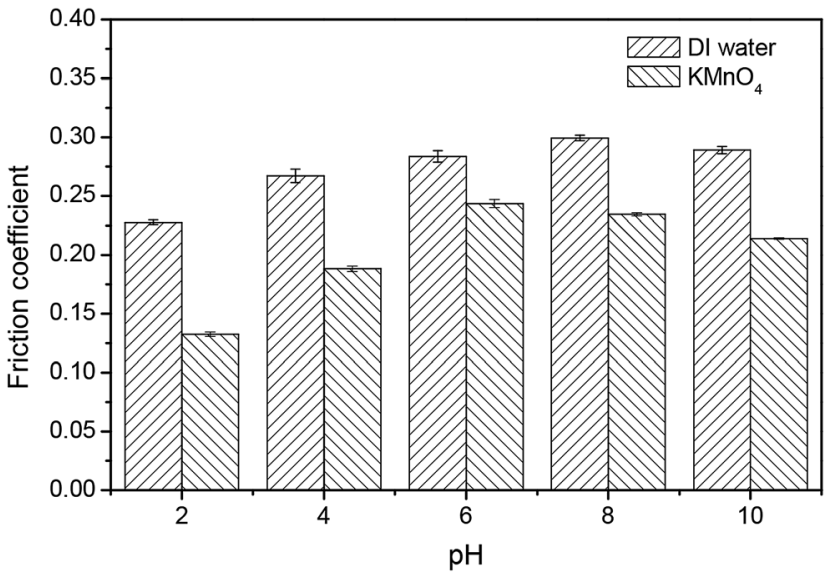

Fig. 10 The friction coefficients between the pad and the $6 \mathrm{H}-\mathrm{SiC}$ substrate surface immersed in $\mathrm{DI}$ water and $\mathrm{KMnO}_{4}$ solution in $\mathrm{pH}$ range $2-10$.

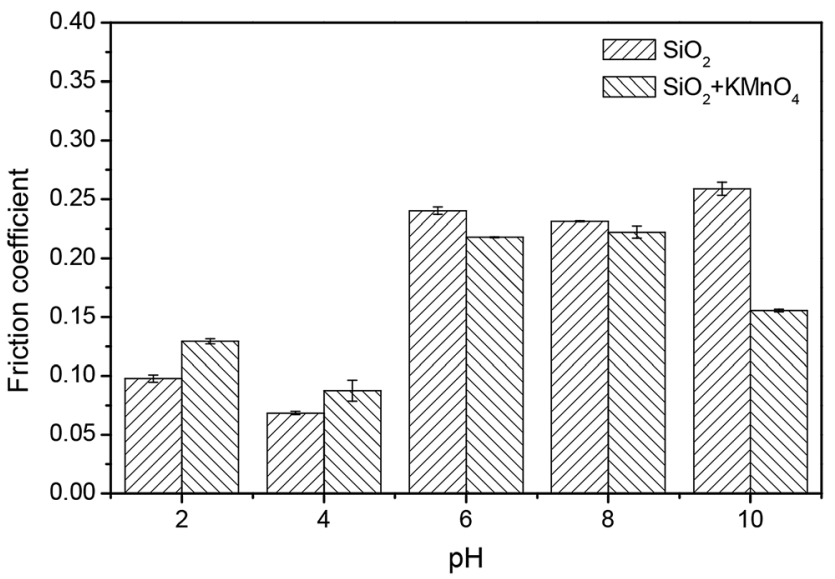

Fig. 11 The friction coefficients between the pad and the $6 \mathrm{H}-\mathrm{SiC}$ substrate surface immersed in the silica based slurries in the absence and presence of $\mathrm{KMnO}_{4}$ in a $\mathrm{pH}$ range of 2-10.

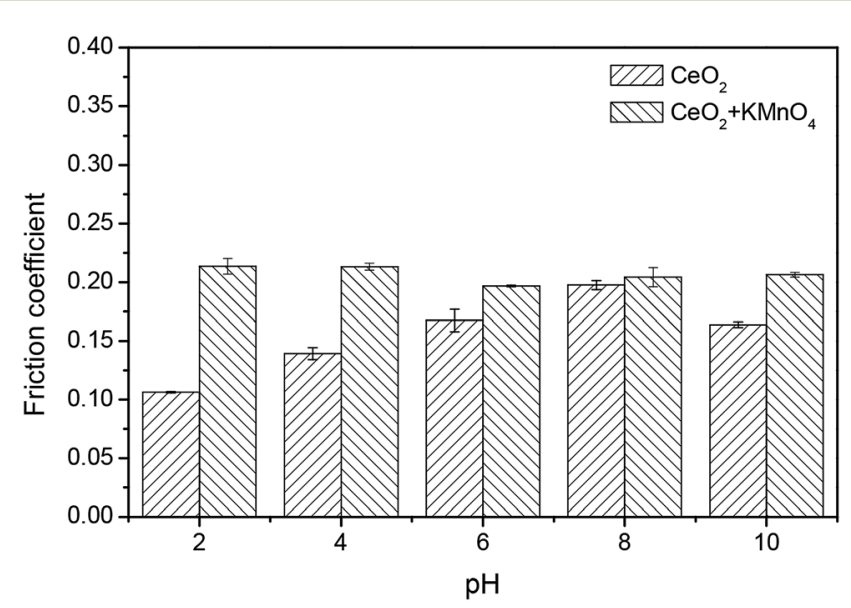

Fig. 12 The friction coefficients between the pad and the $6 \mathrm{H}-\mathrm{SiC}$ substrate surface immersed in the ceria based slurries in the absence and presence of $\mathrm{KMnO}_{4}$ in a $\mathrm{pH}$ range of 2-10. 


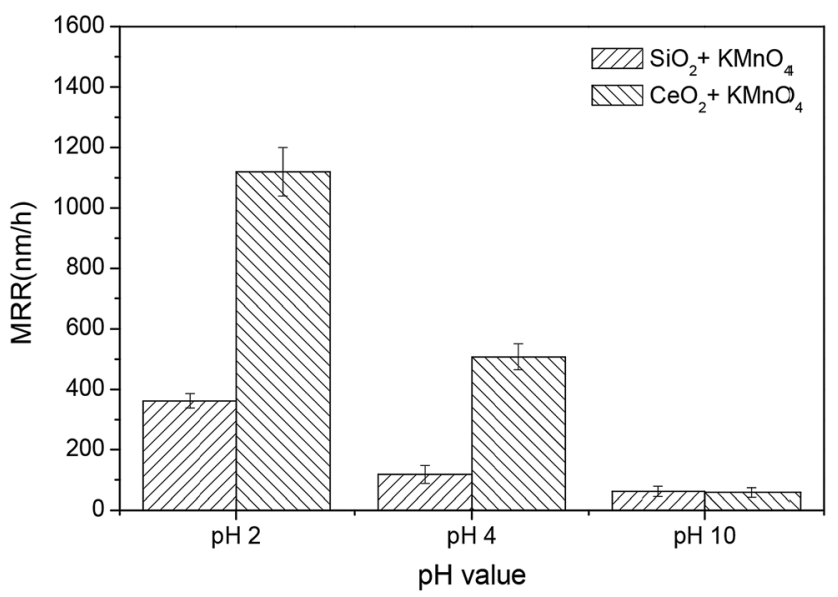

Fig. 13 The MRR of the $6 \mathrm{H}$-SiC substrates polished with silica-based slurries and ceria-based slurries in the presence of $\mathrm{KMnO}_{4}$ at $\mathrm{pH} 2,4$ and 10 . particles were expected to repel the $6 \mathrm{H}$-SiC surface in the $\mathrm{pH}$ range 6 to 10. A similar trend was also observed for the friction coefficients between the pad and the $6 \mathrm{H}-\mathrm{SiC}$ substrate surface immersed in the silica based slurries containing $\mathrm{KMnO}_{4}$ in a $\mathrm{pH}$ range of 2-10.

Fig. 12 demonstrates the friction coefficients between the pad and the $6 \mathrm{H}$-SiC substrate surface immersed in the ceria based slurries in the absence and presence of $\mathrm{KMnO}_{4}$ over $\mathrm{pH}$ values from 2 to 10 . It can be seen that the friction coefficient lubricated by the ceria based slurries increased steadily from $\mathrm{pH} 2$ to $\mathrm{pH} 8$ and then decreased at $\mathrm{pH} 10$, which is in accordance with the adhesion of ceria particles to the $6 \mathrm{H}$-SiC surface from $\mathrm{pH} 2$ to 10 , suggesting that the adhered ceria particles played a role as lubricant. However, the change in the friction coefficient lubricated by the ceria based slurries containing $\mathrm{KMnO}_{4}$ over $\mathrm{pH}$ values from 2 to 10 showed a different trend. It reached a maximum value of 0.21 at $\mathrm{pH} 2$ and then showed no significant change from $\mathrm{pH} 4$ to 10 . A higher shear force might be created by the adhered ceria particles on the oxidized surface during mechanical action, thus increasing the friction coefficient.
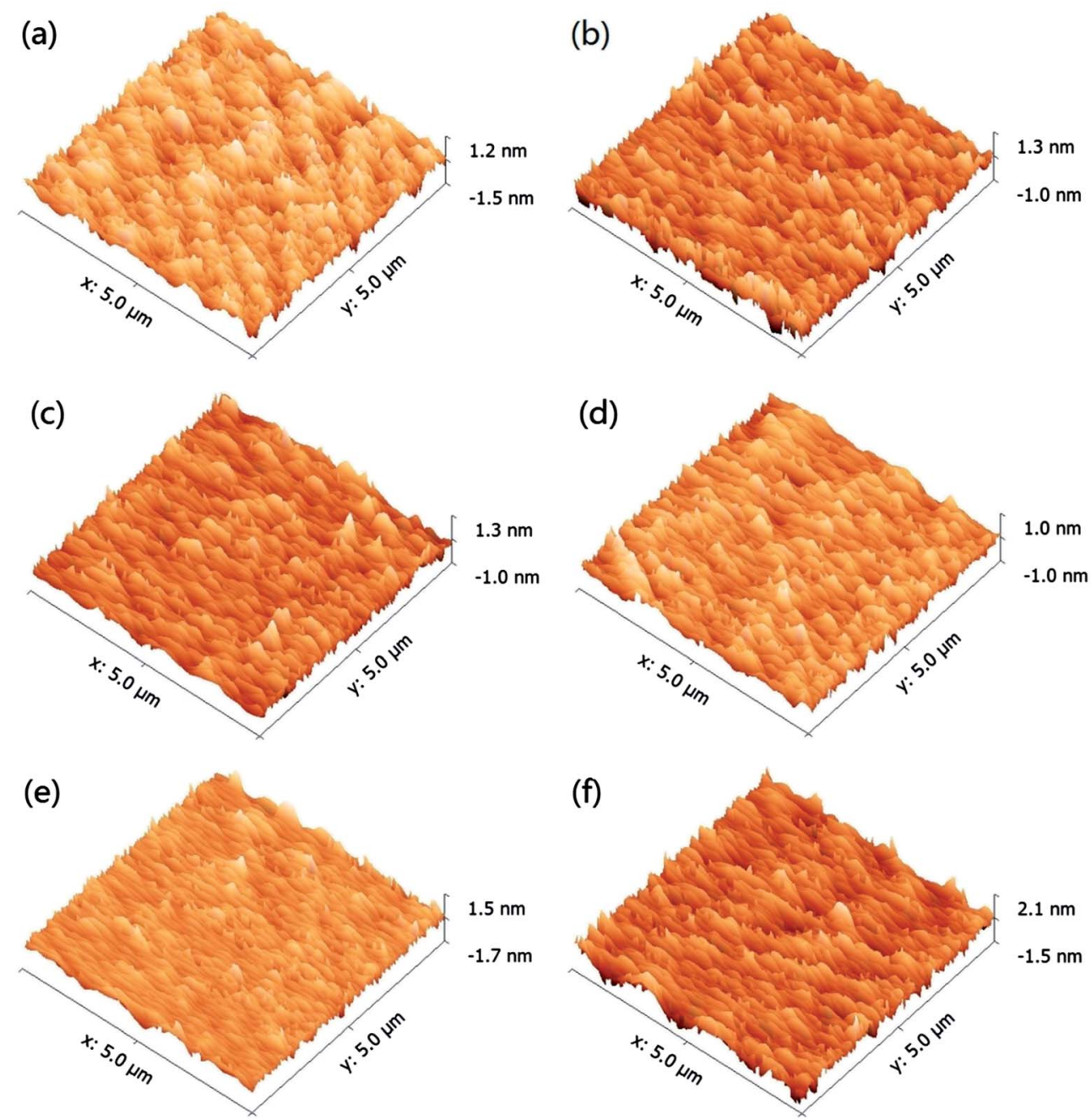

Fig. 14 AFM images of the $6 \mathrm{H}-\mathrm{SiC}$ surfaces polished with silica $+\mathrm{KMnO}_{4}$ based slurries at (a) $\mathrm{pH} 2$, (b) $\mathrm{pH} 4$, (c) $\mathrm{pH} 10$ and with ceria $+\mathrm{KMnO} 4$ based slurries at (d) $\mathrm{pH}$ 2, (e) $\mathrm{pH}$ 4, (f) $\mathrm{pH} 10$. 
It can be seen from the above results that there were some positive correlations between adhesion and friction in the absence of $\mathrm{KMnO}_{4}$. Although the silica and ceria nanoparticles were different in shape and size, they both showed a relatively lower friction coefficient when adhered to the $6 \mathrm{H}$-SiC surfaces. However, when tested in the presence of the $\mathrm{KMnO}_{4}$, there was a noticeable difference in friction coefficients between these two kinds of particles. A considerable increase in friction coefficients could be seen when polished with ceria based slurries containing $\mathrm{KMnO}_{4}$ at $\mathrm{pH} 2$ and $\mathrm{pH}$ 4, whereas it rose slightly when polished with silica based slurries containing $\mathrm{KMnO}_{4}$ at the same $\mathrm{pH}$ values. This could be due to their different electrostatic interactions with the $6 \mathrm{H}$-SiC plate. An attractive force was present between the negatively charged silica particles and the positively charged $6 \mathrm{H}$-SiC surface below $\mathrm{pH} 5$, while the positively charged ceria particles showed a repulsive force. These attracted silica particles hindered the tribochemical reactions between the pad and the wafer surface. In contrast, those adhered ceria particles showed only a negligibly small non-DLVO adhesion force to the wafer surface and this force had less effect on the tribochemical interactions between the pad and the wafer surface. Furthermore, owing to the chemical tooth and the Si-O-Ce bonds, a higher shear force might be created by the adhered ceria particles on the oxidized $6 \mathrm{H}$-SiC surface during the mechanical action, especially in a strongly acid $\mathrm{KMnO}_{4}$ environment, thus increasing the friction coefficient.

\subsection{Polishing of Si-face $6 \mathrm{H}-\mathrm{SiC}$ substrates}

Fig. 13 compares the MRR of the $6 \mathrm{H}$-SiC substrates polished with silica-based slurries and ceria-based slurries in the presence of $\mathrm{KMnO}_{4}$ at $\mathrm{pH} \mathrm{2,4}$ and 10. It can be clearly seen that the MRRs of the $6 \mathrm{H}$-SiC substrates polished with two different slurries both decreased with the increase in $\mathrm{pH}$ values, likely due to the fact that the oxidizing capacities of the polishing slurries were reduced with the addition of $\mathrm{OH}^{-}$. However, the MRRs of the $6 \mathrm{H}$-SiC substrates were significantly higher when polished with the ceria-based slurries than with silica-based slurries at $\mathrm{pH} 2$ and $\mathrm{pH}$, which were in good agreement with the point that surface oxidation was hindered by the electrostatic adsorption of silica particles onto the $6 \mathrm{H}-\mathrm{SiC}$ substrate surfaces below pH 5 during the CMP process. The AFM images of the polished $6 \mathrm{H}$-SiC surfaces are shown in Fig. 14 and the respective average roughness $R_{\mathrm{a}}$ values are presented in Fig. 15. As can be clearly seen, the $R_{\mathrm{a}}$ values of the polished $6 \mathrm{H}-\mathrm{SiC}$ substrates were around $0.2 \mathrm{~nm}$, indicating that the adsorption of abrasive particles had no significant influence on the surface quality of the polished $6 \mathrm{H}-\mathrm{SiC}$ substrates. However, the adsorbed adhesive particles would cause particle contamination on the polished surfaces.

\subsection{XPS analysis}

XPS survey scans were performed on the as-received, prepolished and dipped $6 \mathrm{H}$-SiC substrate surfaces, as shown in Fig. 16. Peaks corresponding to the Si 2s, Si 2p, C 1s and O 1s photoelectrons can be clearly seen and the spectra were similar

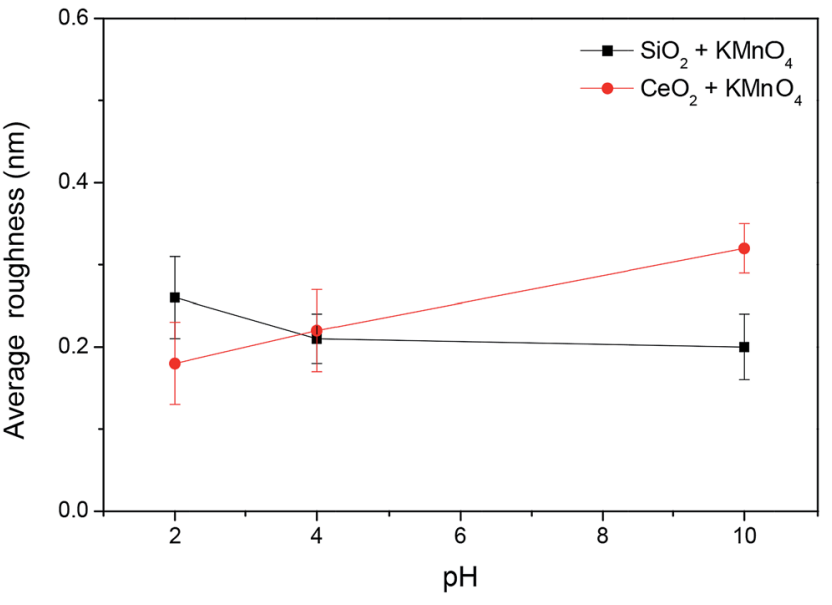

Fig. 15 The surface roughness of $6 \mathrm{H}$-SiC substrates polished with silica-based slurries and ceria-based slurries in the presence of $\mathrm{KMnO}_{4}$ at $\mathrm{pH} 2,4$ and 10.

except for a shorter $\mathrm{C}$ 1s peak in the pre-polished $6 \mathrm{H}-\mathrm{SiC}$ surface. Furthermore, a measurable Mn 2p peak was observed on the $6 \mathrm{H}$-SiC substrate surface when dipped in the $\mathrm{KMnO}_{4}$ solution and which weakened when followed by immersion in the $\mathrm{KOH}$ solution.

Table 1 compares the atomic compositions (\%) of the $6 \mathrm{H}-\mathrm{SiC}$ substrate surfaces treated with different processes. It can be seen that the ratio of $\mathrm{C} / \mathrm{Si}$ and $\mathrm{O} / \mathrm{Si}$ in the as-received and oxidized $6 \mathrm{H}$-SiC surfaces were higher than in the pre-polished and dissolved $6 \mathrm{H}$-SiC surfaces. The change in the $\mathrm{O} / \mathrm{Si}$ ratio indicates that the native oxide layer on the as-received $6 \mathrm{H}-\mathrm{SiC}$ surface was removed during the pre-polishing process and a new oxide layer was formed on the $6 \mathrm{H}$-SiC surface after dipping in the $\mathrm{KMnO}_{4}$ solution. Then this oxide layer could be dissolved into the $\mathrm{KOH}$ solution at $\mathrm{pH}$ 12. Meanwhile, a measurable concentration of $\mathrm{Mn}$ was observed on the dipped $6 \mathrm{H}$-SiC surface. Furthermore, the $\mathrm{C} / \mathrm{Si}$ ratio of the four $6 \mathrm{H}$-SiC surfaces was significantly higher than the normal stoichiometric value of 1 .

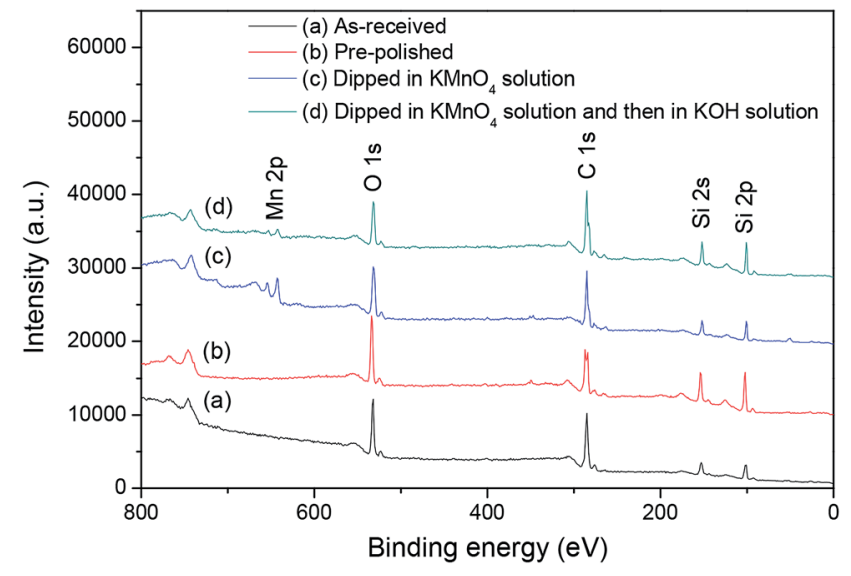

Fig. 16 XPS survey scans of the $6 \mathrm{H}-\mathrm{SiC}$ surfaces: (a) as-received; (b) pre-polished; (c) dipped in $\mathrm{KMnO}_{4}$ solution; (d) dipped in $\mathrm{KMnO}_{4}$ solution and then in $\mathrm{KOH}$ solution. 
Table 1 Atomic concentrations (\%) of the $6 \mathrm{H}-\mathrm{SiC}$ surfaces treated with different processes

\begin{tabular}{|c|c|c|c|c|c|c|}
\hline & C $1 \mathrm{~s}$ & $\mathrm{O} 1 \mathrm{~s}$ & Si $2 p$ & Mn 2p & $\mathrm{C} / \mathrm{Si}$ & $\mathrm{O} / \mathrm{Si}$ \\
\hline As-received & 58.0 & 25.0 & 17.0 & 0 & 3.4 & 1.5 \\
\hline Pre-polished & 47.8 & 23.4 & 27.2 & 0 & 1.8 & 0.9 \\
\hline Dipped in $\mathrm{KMnO}_{4}$ solution and then in & 57.2 & 18.6 & 21.5 & 1.5 & 2.7 & 0.9 \\
\hline
\end{tabular}

KOH solution

The chemical states of the silicon and carbon atoms on the as-received, pre-polished, dipped $6 \mathrm{H}-\mathrm{SiC}$ substrate surfaces were analyzed, as shown in Fig. 17. The Si 2p spectra on the $6 \mathrm{H}-$ SiC surface can be classified into four types: Si-C (100.4 eV), Si$\mathrm{C}-\mathrm{O}(101.1 \mathrm{eV}), \mathrm{Si}-\mathrm{O}_{x}-\mathrm{C}_{y}(101.9 \mathrm{eV})$ and $\mathrm{Si}-\mathrm{O}_{2}(103.0 \mathrm{eV})$, as shown in Si 2p curve-fitting results of Fig. 17(a), (c), (e) and (g). ${ }^{45-48}$ It can be seen that the intensities of $\mathrm{Si}-\mathrm{O}_{x}-\mathrm{C}_{y}$ and $\mathrm{Si}-\mathrm{O}_{2}$ were significantly higher on the as-received SiC substrate surface than on the pre-polished surface, indicating that the removal of native oxide occurred during the polishing process. Upon wet etching in $\mathrm{KOH}$ solution at $\mathrm{pH} 12$, the $\mathrm{Si}-\mathrm{O}_{2}$ peak was almost eliminated (Fig. 16g), implying that the $\mathrm{Si}-\mathrm{O}_{2}$ component could be dissolved in the alkaline solution. The intensity of the $\mathrm{Si}-\mathrm{C}$ component decreased dramatically on the oxidized $6 \mathrm{H}$ SiC surface and then rose sharply after the dissolution process. The $\mathrm{C}$ 1s spectra consisted of six peaks which were $\mathrm{SiC}$ (282.4 $\mathrm{eV}), \mathrm{Si}_{4} \mathrm{C}_{4-x} \mathrm{O}_{2}(283.2 \mathrm{eV}), \mathrm{C}-\mathrm{C} / \mathrm{C}-\mathrm{H}(284.6 \mathrm{eV}) \mathrm{Si}_{4} \mathrm{C}_{4} \mathrm{O}_{4}(285.1$ $\mathrm{eV}), \mathrm{C}-\mathrm{O}(286.1 \mathrm{eV})$ and $\mathrm{C}=\mathrm{O}(288 \mathrm{eV})$, as demonstrated in Fig. 17(b), (d), (f) and (h). ${ }^{45-49}$ The peak of $\mathrm{C}-\mathrm{C} / \mathrm{C}-\mathrm{H}$ could be attributed to the contamination of the $6 \mathrm{H}$-SiC substrate surface or to the ambient, ${ }^{45}$ resulting in a high surface $\mathrm{C} / \mathrm{Si}$ ratio on the $6 \mathrm{H}$-SiC surface (as shown in Table 1). The peak intensity of the SiC component on the $6 \mathrm{H}-\mathrm{SiC}$ surface also increased during the pre-polishing process and decreased dramatically when dipped in the $\mathrm{KMnO}_{4}$ solution, then rose again after immersion in the alkaline solution.

Table 2 compares the relative proportions (\%) of the different chemical components on the as-received, pre-polished and dipped $6 \mathrm{H}-\mathrm{SiC}$ substrate surfaces. From the data given in Table 2, it can be clearly seen that the concentrations of $\mathrm{Si}-\mathrm{O}_{x}-$ $\mathrm{C}_{y}, \mathrm{SiO}_{2}, \mathrm{Si}_{4} \mathrm{C}_{4} \mathrm{O}_{4}, \mathrm{C}-\mathrm{O}$ and $\mathrm{C}=\mathrm{O}$ decreased dramatically on the pre-polished $6 \mathrm{H}-\mathrm{SiC}$ surface, while the concentration $\mathrm{Si}-\mathrm{C}$ increased a lot, compared to the as-received $6 \mathrm{H}$-SiC surface. Furthermore, the total concentrations of oxide species on the $6 \mathrm{H}$-SiC surface dipped in $\mathrm{KMnO}_{4}$ solution were significantly higher than on the pre-polished $6 \mathrm{H}$-SiC surface, indicating that the surface atoms of SiC were oxidized in the presence of oxidant during immersion. When this oxidized surface was further etched in alkaline solution, the total concentrations of oxide species decreased sharply, suggesting that the oxidized layer obtained after dipping in $\mathrm{KMnO}_{4}$ solution could be removed with $\mathrm{KOH}$ solution at a $\mathrm{pH}$ of about 12 .

\subsection{The influence of the particle-wafer interaction in the $6 \mathrm{H}-$ SiC CMP}

The interactions between the abrasive particles and the $6 \mathrm{H}-\mathrm{SiC}$ substrate play a significant role in the $6 \mathrm{H}-\mathrm{SiC}$ CMP process.
According to the remarkably different performances in the CMP of $6 \mathrm{H}-\mathrm{SiC}$ between the silica-based slurries and the ceria-based slurries, ${ }^{9}$ the interaction has a tremendous impact on the surface oxidation of the $6 \mathrm{H}$-SiC substrate and affects the removal of the oxide layer in mechanical abrasion as well.

During the $6 \mathrm{H}-\mathrm{SiC}$ CMP process, the atoms on the $6 \mathrm{H}-\mathrm{SiC}$ surface could be further oxidized into the oxidation species (e.g. $\mathrm{Si}-\mathrm{C}-\mathrm{O}, \mathrm{Si}-\mathrm{O}_{x}-\mathrm{C}_{y}, \mathrm{Si}-\mathrm{O}_{2}, \mathrm{Si}_{4}-\mathrm{C}_{4-x}-\mathrm{O}_{2}, \mathrm{Si}_{4}-\mathrm{C}_{4}-\mathrm{O}_{4}$ and $\mathrm{C}-\mathrm{O}$ ) in the presence of oxidizer and this soft layer consisting of oxidation species (e.g. $\mathrm{Si}-\mathrm{O}_{x}-\mathrm{C}_{y}, \mathrm{Si}-\mathrm{O}_{2}, \mathrm{Si}_{4}-\mathrm{C}_{4}-\mathrm{O}_{4}$ and $\mathrm{C}-\mathrm{O}$ ) might first be removed under mechanical abrasion (as shown in Table 2).

Based on the results of the zeta potentials of the abrasive particles and the DLVO interactions between the $6 \mathrm{H}-\mathrm{SiC}$ wafer surface and nanoparticles, silica particles are prone to adhere to the Si-face $6 \mathrm{H}$-SiC surface below $\mathrm{pH} 5$, while ceria particles are expected to be repelled by the $6 \mathrm{H}$-SiC surface with the same charge. However, a lot of ceria particles still exist on these sample surfaces at $\mathrm{pH} 2, \mathrm{pH} 4$ and $\mathrm{pH}$ 10. This may be because the ceria particle process a chemical tooth and $\mathrm{Si}-\mathrm{O}-\mathrm{Ce}$ bonds are formed between ceria particles and the sample surface.

During the CMP processes, the friction coefficient was reduced significantly by the adhesion of silica/ceria nanoparticles onto the $6 \mathrm{H}-\mathrm{SiC}$ substrate surface in the absence of $\mathrm{KMnO}_{4}$. However, the MRR and the friction coefficients were most affected by the electrostatic adsorption of silica particles on the Si-face $6 \mathrm{H}$-SiC surface below $\mathrm{pH} 5$ in the presence of $\mathrm{KMnO}_{4}$, while this phenomenon was not observed when ceria particles were adsorbed.

On the basis of the XPS analysis of the $6 \mathrm{H}$-SiC substrate surfaces, oxidized species were formed on the $6 \mathrm{H}-\mathrm{SiC}$ surface in the presence of $\mathrm{KMnO}_{4}$. Furthermore, the adhesion of abrasive particles onto the oxidized $6 \mathrm{H}$-SiC surfaces could increase the effective contact area between the abrasives and the $6 \mathrm{H}-\mathrm{SiC}$ surface during the mechanical abrasion, thus facilitating its material removal.

To summarize the above discussion, in order to achieve a defect-free $6 \mathrm{H}$-SiC surface with a high material removal rate during CMP, the ideal electrostatic interactions between the abrasive particles and the $6 \mathrm{H}-\mathrm{SiC}$ substrate surface are required to meet two conditions: firstly, the abrasives need to be repelled from the substrate surface so that the surface oxidation could occur easily on the $6 \mathrm{H}-\mathrm{SiC}$ surface when polished in the presence of $\mathrm{KMnO}_{4}$ below pH 5; secondly, the abrasive particles need to attach rapidly to the oxidized surface. Then both of them could be removed quickly through the mechanical abrasion force. In addition, this deduction of the electrostatic 

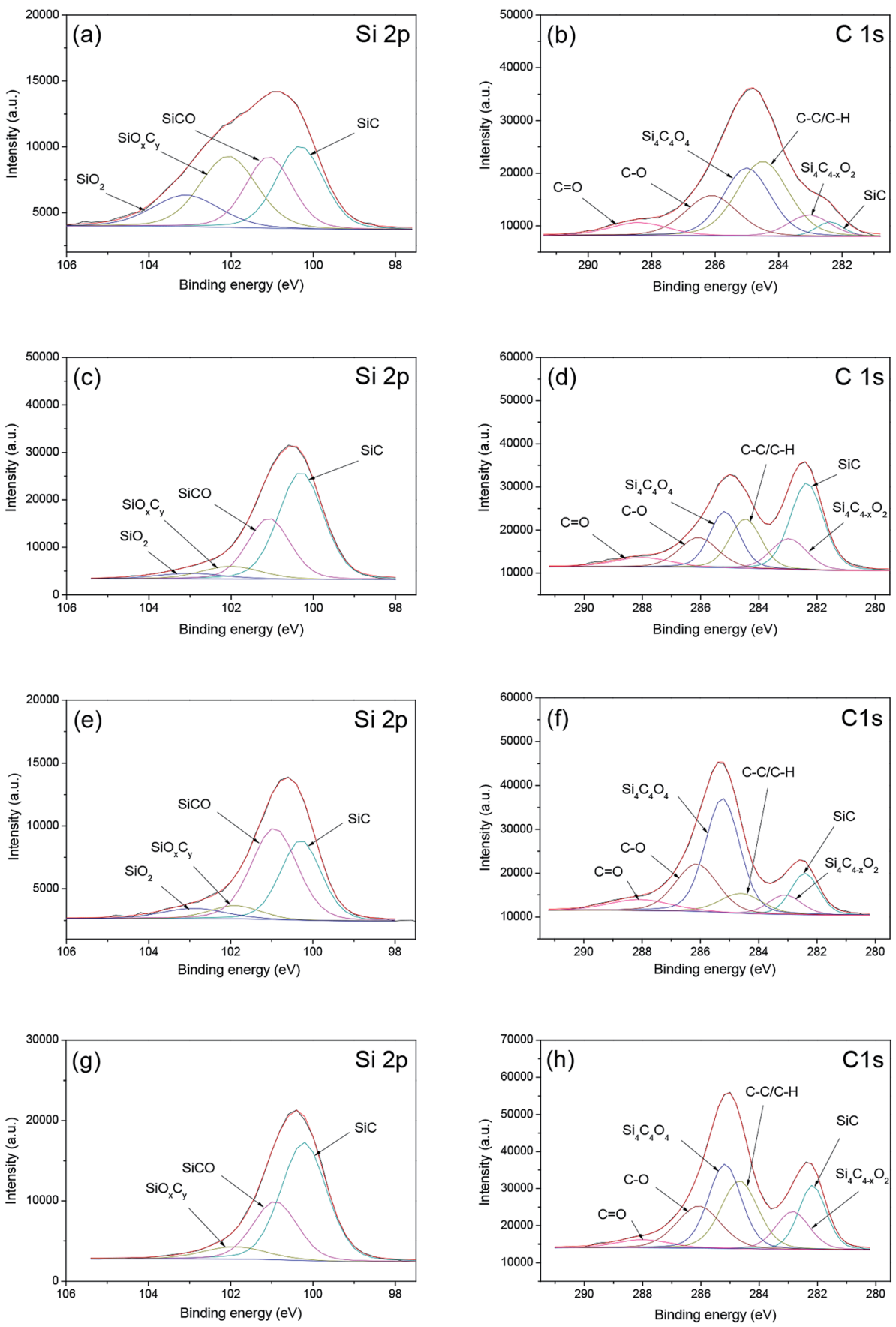

Fig. 17 Si $2 p$ and $\mathrm{C}$ 1s spectra of the $6 \mathrm{H}$-SiC surfaces: ( $\mathrm{a}$ and b) as-received; (c and d) pre-polished; (e and f) dipped in $\mathrm{KMnO}_{4}$ solution; ( $\mathrm{g}$ and $\mathrm{h}$ ) dipped in $\mathrm{KMnO}_{4}$ solution and then in $\mathrm{KOH}$ solution.

interactions during the CMP process was in good agreement with the results of polishing experiments as well as with our previous study on the Si-face $6 \mathrm{H}$-SiC CMP performance under $\mathrm{KMnO}_{4}$ containing slurries. ${ }^{9}$

Finally, some points need to be clarified. Firstly, the preferred crystallographic orientation of SiC could be studied to provide an exact insight into the mechanism of the interaction. However, we compared the XRD results of pre-polished $6 \mathrm{H}-\mathrm{SiC}$ substrate with substrates dipped in five different slurries (0.05 $\mathrm{M} \mathrm{KMnO}_{4}$ solution, $6 \mathrm{wt} \%$ silica slurry at $\mathrm{pH} 4,6 \mathrm{wt} \%$ silica slurry containing $0.05 \mathrm{M} \mathrm{KMnO}_{4}$ at $\mathrm{pH} \mathrm{4,2} \mathrm{wt \%} \mathrm{ceria} \mathrm{slurry} \mathrm{at}$ $\mathrm{pH} 4$ and $2 \mathrm{wt} \%$ ceria slurry containing $0.05 \mathrm{M} \mathrm{KMnO}_{4}$ at $\mathrm{pH} 4$ ) for $3 \mathrm{~h}$. According to the XRD study, there was no significant difference between the pre-polished substrate surface and the dipped sample surface. Secondly, the interactions of abrasive particles and the SiC surface could be affected by surfaces with different oxidation degrees. It could be very meaningful to vary the oxidation degree of the SiC surface and study the interactions at a defined $\mathrm{pH}$ value. However, due to the high chemical stability of the SiC single crystal, it was hard to change the 
Table 2 Relative proportions of the different chemical components on the $6 \mathrm{H}$-SiC surfaces

\begin{tabular}{|c|c|c|c|c|c|}
\hline & & As-received & Pre-polished & $\begin{array}{l}\text { Dipped in } \mathrm{KMnO}_{4} \\
\text { solution }\end{array}$ & $\begin{array}{l}\text { Dipped in } \mathrm{KMnO}_{4} \\
\text { solution and then } \\
\text { in } \mathrm{KOH} \text { solution }\end{array}$ \\
\hline & $\mathrm{Si}-\mathrm{C}-\mathrm{O}$ & 24.7 & 30.4 & 48.2 & 30.8 \\
\hline & $\mathrm{Si}-\mathrm{O}_{x}-\mathrm{C}_{y}$ & 30.2 & 8.8 & 7.5 & 7.7 \\
\hline & $\mathrm{Si}-\mathrm{O}_{2}$ & 15.7 & 4.3 & 7.1 & - \\
\hline & $\mathrm{Si}_{4}-\mathrm{C}_{4}-\mathrm{O}_{4}$ & 43.6 & 22.9 & 46.7 & 34.6 \\
\hline & $\mathrm{C}-\mathrm{O}$ & 28.6 & 15.8 & 23.8 & 22.9 \\
\hline & $\mathrm{C}=\mathrm{O}$ & 10.2 & 7.1 & 8.1 & 5.2 \\
\hline
\end{tabular}

oxidation of the SiC surface to a particular degree during the static dipping process. This could be achieved with the development of technology in the future.

\section{Conclusions}

The influence of the interaction between $\mathrm{SiO}_{2}$ or $\mathrm{CeO}_{2}$ nanoparticles and the Si-face (0001) $6 \mathrm{H}$-SiC substrate surface in different slurries with varied $\mathrm{pH}$ values were investigated using zeta potential measurements, SEM observations, DLVO theoretical predictions, friction tests, polishing experiments and XPS analysis. Silica particles were prone to adhere to the Si-face $6 \mathrm{H}$ SiC surface below pH 5, while ceria particles were expected to be repelled by the similarly charged $6 \mathrm{H}-\mathrm{SiC}$ surface. However, a lot of ceria particles still existed on $6 \mathrm{H}-\mathrm{SiC}$ substrate surfaces at pH 2, pH 4 and $\mathrm{pH} 10$, due to the fact that the ceria particle processes a chemical tooth and $\mathrm{Si}-\mathrm{O}-\mathrm{Ce}$ bonds are formed between ceria particles and the sample surface. The theoretical predictions of DLVO forces between the surfaces of the $6 \mathrm{H}-\mathrm{SiC}$ substrate and the silica nanoparticles were in good agreement with the experimental phenomena. While in the case of ceria nanoparticles, discrepancies between theoretical predictions and experimental observations were observed, due to the existence of non-DLVO interactions between the surfaces of the ceria particles and the $6 \mathrm{H}$-SiC plate, such as the chemical tooth possessed by the ceria particles and the $\mathrm{Si}-\mathrm{O}-\mathrm{Ce}$ bonds formed between ceria particles and the $6 \mathrm{H}-\mathrm{SiC}$ surface. The friction coefficients between the pad and the $6 \mathrm{H}-\mathrm{SiC}$ substrate surface could be reduced by the adhesion of silica or ceria particles which acted as ball bearings in the absence of $\mathrm{KMnO}_{4}$. However, there was a significant difference in the friction coefficients and polishing performance between the adhesion of silica and ceria particles in the presence of $\mathrm{KMnO}_{4}$ below pH 5. The XPS analysis indicated that the oxide layer of $6 \mathrm{H}-\mathrm{SiC}$ substrate could be removed through the mechanical action of abrasive particles and regenerated in the presence of oxidants during the CMP process.

\section{Acknowledgements}

This work was supported by the National Natural Science Foundation of China (Grant No. 51305166, 51675232) and the
Natural Science Foundation of Jiangsu Province, China (Grant No. BK20130143).

\section{References}

1 Y. Zhou, G. S. Pan, X. L. Shi, H. Gong, G. H. Luo and Z. H. Gu, Chemical mechanical planarization (CMP) of on-axis Si-face SiC wafer using catalyst nanoparticles in slurry, Surf. Coat. Technol., 2014, 251(1), 48-55.

2 J. Watanabe, G. Yu, O. Eryu, I. Koshiyama, K. Izumi, K. Makashima, M. Umeno, T. Jimbo and K. Kodama, High precision chemical mechanical polishing of highly-borondoped Si wafer used for epitaxial substrate, Precis. Eng., 2005, 29(2), 151-156.

3 H. L. Zhu, L. A. Tessaroto and S. Robert, Chemical mechanical polishing (CMP) anisotropy in sapphire, Appl. Surf. Sci., 2004, 236(1-4), 120-130.

4 O. Eryu, K. Abe and N. Takemoto, Nanostructure formation of SiC using ion implantation and CMP, Nucl. Instrum. Methods Phys. Res., Sect. B, 2006, 242(1-2), 237-239.

5 L. Dong, G. S. Sun and J. Yu, Growth of $4 \mathrm{H}-\mathrm{SiC}$ epilayers with low surface roughness and morphological defects density on $4^{\circ}$ off-axis substrates, Appl. Surf. Sci., 2013, 270, 301-306.

6 X. F. Chen, X. G. Xu, J. Li, S. Z. Jiang, L. Ning, Y. M. Wang, D. Y. Ma, X. B. Hu and M. H. Jiang, Surface Polishing of 6H-SiC Substrates, J. Mater. Sci. Technol., 2007, 23(3), 430432.

7 X. L. Shi, G. S. Pan, Y. Zhou, Z. H. Gu, H. Gong and C. L. Zou, Characterization of colloidal silica abrasives with different sizes and their chemical-mechanical polishing performance on 4H-SiC (0001), Appl. Surf. Sci., 2014, 307, 414-427.

8 H. Lee, B. Park, S. Jeong, S. Joo and H. Jeong, The effect of mixed abrasive slurry on CMP of $6 \mathrm{H}-\mathrm{SiC}$ substrates, $J$. Ceram. Process. Res., 2009, 10(3), 378-381.

9 G. M. Chen, Z. F. Ni, L. J. Xu, Q. Z. Li and Y. W. Zhao, Performance of Colloidal Silica and Ceria Based slurries on CMP of Si-face 6H-SiC substrates, Appl. Surf. Sci., 2015, 359, 664-668.

10 H. Deng, K. Hosoya, Y. Imanishi, K. Endo and K. Yamamura, Electro-chemical mechanical polishing of single-crystal SiC using $\mathrm{CeO}_{2}$ slurry, Electrochem. Commun., 2015, 52, 5-8. 
11 L. Zhou, V. Audurier and P. Pirouz, Chemomechanical polishing of silicon carbide, J. Electrochem. Soc., 1997, 144(6), 161-163.

12 K. Yagi, J. Murata, A. Kubota, Y. Sano, H. Hara, T. Okamoto, K. Arima, H. Mimura and K. Yamauchi, Catalyst-referred etching of $4 \mathrm{HSiC}$ substrate utilizing hydroxyl radicals generated from hydrogen peroxide molecules, Surf. Interface Anal., 2010, 40(6-7), 998-1001.

13 C. H. Li, I. B. Bhat, R. J. Wang and J. Seiler, Electro-chemical mechanical polishing of silicon carbide, J. Electron. Mater., 2004, 33(5), 481-486.

14 H. Deng, K. Hosoya, Y. Imanishi, K. Endo and K. Yamamura, Electro-chemical mechanical polishing of single-crystal SiC using $\mathrm{CeO}_{2}$, slurry, Electrochem. Commun., 2015, 52, 5-8.

15 D. O. Volkov, P. R. V. Dandu, H. Goodman, B. Santora and I. Sokolov, Influence of adhesion of silica and ceria abrasive nanoparticles on chemical-mechanical planarization of silica surfaces, Appl. Surf. Sci., 2011, 257(20), 8518-8524.

16 Z. Y. Lu, N. P. Ryde, S. V. Babu and E. Matijevic, Particle adhesion studies relevant to chemical mechanical polishing, Langmuir, 2005, 21(22), 9866-9872.

17 J. T. Abiade, W. Choi and R. K. Singh, Effect of pH on ceriasilica interactions during chemical mechanical polishing, $J$. Mater. Res., 2005, 20(05), 1139-1145.

18 T. S. Sreeremya, M. Prabhakaran and S. Ghosh, Tailoring the surface properties of cerium oxide nanoabrasives through morphology control for glass CMP, RSC Adv., 2015, 5(102), 84056-84065.

19 R. Manivannan, S. N. Victoria and S. Ramanathan, Mechanism of high selectivity in ceria based shallow trench isolation chemical mechanical polishing slurries, Thin Solid Films, 2010, 518(20), 5737-5740.

20 P. R. V. Dandu, V. K. Devarapalli and S. V. Babu, Reverse selectivity-high silicon nitride and low silicon dioxide removal rates using ceria abrasive-based dispersions, $J$. Colloid Interface Sci., 2010, 347(2), 267-276.

21 U. R. K. Lagudu, S. Isono, S. Krishnan and S. V. Babu, Role of ionic strength in chemical mechanical polishing of silicon carbide using silica slurries, Colloids Surf., A, 2014, 445(6), 119-127.

22 H. Lee, B. Park, S. Jeong and H. Jeong, The effect of mixed abrasive slurry on CMP of $6 \mathrm{H}-\mathrm{SiC}$ substrates, J. Ceram. Process. Res., 2009, 10(3), 378-381.

23 C. L. Neslen, W. C. Mitchel and R. L. Hengehold, Effects of process parameter variations on the removal rate in chemical mechanical polishing of $4 \mathrm{H}-\mathrm{SiC}, J$. Electron. Mater., 2001, 30(10), 1271-1275.

$24 \mathrm{H}$. Nitta, A. Isobe, P. J. Hong and T. Hirao, Research on reaction method of high removal rate chemical mechanical polishing slurry for $4 \mathrm{H}-\mathrm{SiC}$ substrate, Jpn. J. Appl. Phys., 2011, 50(4), 046501.

25 Y. Chen, J. Lu and Z. Chen, Preparation, characterization and oxide CMP performance of composite polystyrene-core ceria-shell abrasives, Microelectron. Eng., 2011, 88(2), 200205.

26 B. S. Necula, I. Apachitei, L. E. Fratila-Apachitei, C. Teodosiu and J. Duszczyk, Stability of nano-/microsized particles in deionized water and electroless nickel solutions, J. Colloid Interface Sci., 2007, 314(2), 514-522.

27 J. T. K. Quik, I. Lynch, K. V. Hoecke, C. J. H. Miermans, K. A. C. D. Schamphelaere, C. R. Janssen, K. A. Dawson, M. A. C. Stuart and D. V. D. Meent, Effect of natural organic matter on cerium dioxide nanoparticles settling in model fresh water, Chemosphere, 2010, 81(6), 711-715.

28 S. H. Chung, D. W. Lee, M. S. Kim and K. Y. Lee, The synthesis of silica and silica-ceria, core-shell nanoparticles in a water-in-oil (W/O) microemulsion composed of heptane and water with the binary surfactants AOT and NP-5, J. Colloid Interface Sci., 2011, 355(1), 70-75.

29 B. P. Singh, J. Jena, L. Besra and S. Bhattacharjee, Dispersion of nano-silicon carbide (SiC) powder in aqueous suspensions, J. Nanopart. Res., 2007, 9(5), 797-806.

30 K. Dawkins, B. W. Rudyk, Z. Xu and K. Cadien, The pHdependant attachment of ceria nanoparticles to silica using surface analytical techniques, Appl. Surf. Sci., 2015, 345, 249-255.

31 R. K. Iler, The Chemistry of silica: solubility, polymerization, colloid and surface properties, and biochemistry, John Wiley and Sons, 1979.

32 T. Hoshino, Y. Kurata, Y. Terasaki and K. Susa, Mechanism of polishing of $\mathrm{SiO}_{2}$ films by $\mathrm{CeO}_{2}$ particles, J. Non-Cryst. Solids, 2001, 283, 129-136.

33 C. Wu, L. Wang, D. Harbottle, J. Masliyah and Z. Xu, Studying bubble-particle interactions by zeta potential distribution analysis, J. Colloid Interface Sci., 2015, 449, 399-408.

34 C. Zhan and R. K. Singh, Mechanism of particle deposition on silicon surface during dilute HF cleans, J. Electrochem. Soc., 2003, 150(11), G667-G672.

35 B. V. Derjaguin, N. V. Churaev and V. M. Muller, Surface forces, Springer, US, 1987.

36 E. M. V. Hoek and G. K. Agarwal, Extended DLVO interactions between spherical particles and rough surfaces, J. Colloid Interface Sci., 2006, 298(1), 50-58.

37 M. Hermansson, The DLVO theory in microbial adhesion, Colloids Surf., B, 1999, 14(1-4), 105-119.

38 B. A. Krajina, L. S. Kocherlakota and R. M. Overney, Direct determination of the local Hamaker constant of inorganic surfaces based on scanning force microscopy, J. Chem. Phys., 2014, 141(16), 164707.

$39 \mathrm{H}$. Roger, Origins and applications of London dispersion forces and Hamaker constants in ceramics, J. Am. Ceram. Soc., 2000, 83(9), 2117-2146.

40 C. Kong and Y. K. Leong, On the flocculation and agglomeration of ceria dispersion, J. Dispersion Sci. Technol., 2011, 32(9), 1235-1238.

$41 \mathrm{H}$. Karimian and A. A. Babaluo, Halos mechanism in stabilizing of colloidal suspensions: nanoparticle weight fraction and pH effects, J. Eur. Ceram. Soc., 2007, 27(1), 1925.

42 L. Bergstrom, A. Meurk, H. Arwin and D. J. Rowcliffe, Estimation of Hamaker constants of ceramic materials from optical data using Lifshitz theory, J. Am. Ceram. Soc., 2005, 79(2), 339-348. 
43 H. J. Butt and M. Kappl, Surface and interfacial forces, WileyVCH Verlag GmbH \& Co. KGaA, Germany, 2010.

44 Z. Adamczyk and P. Weroński, Application of the DLVO theory for particle deposition problems, Adv. Colloid Interface Sci., 1999, 83(1-3), 137-226.

45 M. Rosso, A. Arafat, K. Schroën, M. Giesbers, C. S. Roper, R. Maboudian and $\mathrm{H}$. Zuilhof, Covalent attachment of organic monolayers to silicon carbide surfaces, Langmuir, 2008, 24(8), 4007-4012.

46 T. Maruyama, H. Bang, N. Fujita, Y. Kawamura, S. Maritsuka and M. Kusunoki, STM and XPS studies of early stages of carbon nanotube growth by surface decomposition of $6 \mathrm{H}$ $\mathrm{SiC}(000 \overline{1})$ under various oxygen pressures, Diamond Relat. Mater., 2007, 16(4-7), 1078-1081.
47 B. Hornetz, H. J. Michel and J. Halbritter, ARXPS studies of $\mathrm{SiO}_{2}-\mathrm{SiC}$ interfaces and oxidation of $6 \mathrm{H}$ SiC single crystal Si-(001) and C-(001) surfaces, J. Mater. Res., 1994, 9(12), 3088-3094.

48 Y. Zhou, G. S. Pan, X. L. Shi, L. Xu, C. L. Zou, H. Gong and G. H. Luo, XPS, UV-vis spectroscopy and AFM studies on removal mechanisms of Si-face $\mathrm{SiC}$ wafer chemical mechanical polishing (CMP), Appl. Surf. Sci., 2014, 316, 643-648.

49 K. Yamamura, T. Takiguchi, M. Ueda, H. Deng, A. N. Hattori and N. Zettsu, Plasma assisted polishing of single crystal SiC for obtaining atomically flat strain-free surface, CIRP Ann., 2011, 60(1), 571-574. 